\title{
Adolesan Dönemde Ekrana Bağlı Aktivitelerin Hamstring Kas Uzunluğu, Reaksiyon Zamanı Ve Vücut Kitle İndeksi Üzerine Etkisi
}

\author{
THE EFFECT OF SCREEN BASED ACTIVITIES ON HAMSTRING MUSCLE LENGTH, REACTION \\ TIME AND BODY MASS INDEX IN ADOLESANS
}

\author{
Müslüm BERBER ${ }^{1}$, Didem KARADİBAK ${ }^{2}$, Sevtap GÜNAY UÇURUM ${ }^{3}$ \\ ${ }^{1}$ Dokuz Eylül Üniversitesi, Sağlık Bilimleri Enstitüsü \\ 2Dokuz Eylül Üniversitesi Fizik Tedavi Ve Rehabilitasyon Yüksek Okulu \\ ${ }^{3}$ Katip Çelebi Üniversitesi, Atatürk Eğitim Araştırma Hastanesi, Fizik Tedavi Ve Rehabilitasyon Departmanı
}

Sevtap GÜNAY UÇURUM İzmir Katip Çelebi Üniversitesi Atatürk Eğitim Araştırma Hastanesi Fizik tedavi ve Rehabilitasyon Bölümü

e-posta:

sevtapgunay.tfd@gmail.com

Tel: (505) 3569770

IZMIR

\section{ÖZET}

Amaç: $\mathrm{Bu}$ çalışma adolesan dönemde ekrana bağlı aktivitelerin hamstring kas uzunluğu, reaksiyon zamanı ve vücut kitle indeksi üzerine etkisini araştırmak amacıyla planlanmıştır.

Yöntemler: Çalışmaya vücudun herhangi bir yerinde kas-iskelet sistemine ait akut ve kronik hastalık öyküsü olmayan 67 öğrenci alındı. Öğrencilerin sosyo-demografik özellikleri, bilişim ve iletişim teknoloji kullanım süreleri ve günlük bilgisayar kullanımı, günlük digital oyun oynama, günlük telefon kullanma, günlük televizyon izleme ve haftalık internet kullanım süreleri sorgulandı. Ayrıca hamstring kas uzunluğu için düz bacak kaldırma testi, reaksiyon zamanı için nelson el reaksiyon testi yapildi.

Bulgular: Çalışma 67 öğrenci ile yapıldı ve bu öğrencilerin yaş ortalamaları 16 $\pm 1,1$ dır. Haftalık 1-13 saat internet kullanan öğrencilerin \%48,6, 14-41 saat internet kullanan öğrencilerin \%33 ve 42 saat internet kullanan öğrencilerin \%66,6'sında hamstring kısalığı görülmüştür. Vücut kitle indeksi sonuçları değerlendirildiğinde, her gün oyun oynamayan öğrencilerin \%64 normal iken,1 saatten az oyun oynayan 9 öğrenciden $5^{\prime}$ inin düşük ve $4^{\prime}$ ünün ise normal olduğu gözlenmiştir. 2-3 saat veya 4-5 saat oyun oynayan öğrencilerin tamamının vücut kitle indeksi normal bulunmuştur. Ancak 5 saatten fazla dijital oyun oynayan 3 ögrenciden 2 'sinin obezitesinin olduğu kaydedilmiştir. Öğrencilerin reaksiyon zamanı ile bilgisayar kullanım süreleri arasında bir ilişki saptanmamıştır $(p>0,05)$.

Sonuç: Haftalık internet kullanım süresi arttıkça hamstring kısalığı görülen öğrenci yüzdesinin arttığı saptanmıştır. Ayrıca günlük 5 saatten fazla oyun oynayan öğrencilerde obezite gelişme riskinin çok yüksek olduğu tespit edilmiştir ve dijital oyun oynama süreleri ile vücut kitle indeksi arasında doğrusal bir ilişki bulunmuştur. Anahtar sözcükler: Adolesan dönem, hamstring kas uzunluğu, reaksiyon zamanı, ekrana bağlı aktiviteler

\section{SUMMARY}

Objective: This study has been carried out to evaluate the effects of screen based activities on hamstring muscle length, reaction time and body mass index in adolesans. Methods: This study was performed on sixty seven students who have not diagnosis of 
acute and chronic musculoskeletal system disease. All students were asked for sociodemographic characteristics and exposure time and they was measured by asking how many hours respondents spent daily information and communication technology, use of computer, playing digital games, use of phone, TV viewing and weekly use of internet. In addition straight leg raising for hamstring muscle length and nelson hand reaction test for reaction time was performed.

Results: This study was performed with 67 students and the mean age of subjects was $16 \pm 1.1$. In $48.6 \%$ of students who were using the $14-41$ hours internet and $66.6 \%$ of students who were using the 42 hours internet was observed in muscle shortening. When the body mass index results were assessed, it was determined that $64 \%$ of students who do not play game every day is normal, 5 of 9 students who play less than 1 hour is lower and 4 students is normal. However, 2 of the 3 students who play more than 5 hour's digital game were noted as obese. Between the reaction time of students and duration of computer use was no relationship $(p>0.05)$.

Conclusion: It was found that increase in weekly use of internet duration increases the percentage of students who has shortness of the hamstring muscle. In addition students who play more than 5 hours per day were found to be very high risk of developing obesity. Additionally there was linear relationship between digital game playing and bady mass index.

Key words: Adolescence period, hamstring muscle length, reaction time, screen based activitie

Ergenlik dönemi (13-17 yaş), çocukluk ile erişkin çă̆ arasındaki biyolojik, zihinsel ve fiziksel değişikliklerin en hızlı olduğu gelişme dönemidir. Ayrıca kişinin, anatomik ve fizyolojik değişimlerinin maksimum düzeyde olduğu, bazen de bu değişikliklere uyumda problemlerin yaşanabildiği bir süreçtir. Yaklaşık yirmi yıl önce, boş zamanlarını bahçelerde veya sokak aralarında oynayarak geçiren çocuklar, günümüzde gelişen teknolojinin ve değişen sosyal yapının da etkisiyle artık zamanlarının çoğunu televizyon ve bilgisayar başında geçirmektedir. Ayrıca, beslenme alışkanlıklarındaki değişimiyle birlikte gençlik döneminde obezite görülme sıklığıda hızla artmaktadır (1). Obezite, çocuk ve adolesanların \%25-30'unu etkileyen önemli bir beslenme problemidir. Çocukluk çağı obezitesi ozellikle gelişmiş ülkelerde olmakla beraber, günümüzde bütün dünyanın ortak sorunlarından biri olarak kabul edilmektedir. Obeziteye bağlı problemlerin yanı sıra çocukluk çağında obez olanlarda erişkin dönemde fiziksel hastalıklara yakalanma riski ve benzer nedenlerden ölüm oranları artmaktadır (2).

Ergenlik dönemine obez girenlerin \%50'si erişkin dönemde obez olmaktadır. Malesef bu durum çoğu kez çocuğun ailesi tarafından tedavi edilmesi gereken bir problem olarak görülmemektedir. Ancak yeterince ciddiye alınmayan ergenlik obezitesi, ileride önemli bir sağlik sorunu olarak karşımıza çıkmaktadır. 1990'dan bu yana bil- gisayar kullanımının yaygınlaştığı bilinmektedir $(2,3)$. Bilgisayar kullanımı ile birlikte iletişim ve bilgilendirme teknolojisinin diğer formları ve sanal oyunlar artmaktadır. Bilgisayar kullanımı çocuklarda ve gençlerde dereceli olarak 1987 - 1988 yılları arasında günlük 11 dakika iken 1999 - 2000 yılları arasında günlük 47 dakikaya çıkmıştır. Aktivite olarak bilgisayar kullanımı veya sanal oyun oynamak oturma postürü açısından birbirine benzemektedir (4).

Ergen kişilerin bilgisayar önünde geçirdikleri yoğun zaman dilimleri, obeziteye ve özellikle arka bacak kas gruplarında kısalıklara neden olmaktadır. Hareketsizlik obezite riskini arttırmakta, obazitede hareketsizliğe yol açmaktadır (5-7). Özellikle uzun süreli oturularak yapılan bilgisayar başında harcanan zaman gibi, kas kısalığını arttırmakta; kaslarda kısalma ise yaralanma riskini tetiklemektedir. Günümüzde fiziksel şikâyetlere paralel olarak gençlerin ekrana bağlı aktiviteleri de artmıştır. Çünkü ekrana bağlı aktiviteler ekranın şekline ve pozisyonuna göre sürekli bir sabit fiziksel pozisyon gerektirmektedir (8).

Çalışmamızın hipotezi; gençlerin uzun süreli bilgisayar kullanımlarının, özellikle uzun süreli masa başı oturmasına bağlı olarak arka bacak kas (hemstring grubu) kısalığını, ve vücut beden kitle indeksini dolayısıyla obezite riskini arttırması yönündedir. 


\section{GEREÇ VE YÖNTEM}

Araştırmaya, İzmir Büyükçiğli Özel Türk Koleji'nde öğrenim gören 67 öğrenci alındı. Lisede öğrenim gören ve çalışmaya katılmaya gönüllü, akut veya kronik bir hastalık öyküsü ile muskuloskeletal yetersizliği olmayan bütün öğrenciler çalışmaya dahil edildi. Çalışmaya başlamadan önce yapılacak değerlendirmeler ve çalışmanın amacı tüm öğrencilere anlatıldı ve aydınlatılmış onam alındı.

Olguların sosyo-demografik özellikleri karşılıklı görüşme yöntemi ile kaydedildi. Vücut Kitle İndeksi (VKİ), kilogram cinsinden vücut ağırlığının, metre cinsinden boy uzunluğunun karesine oranı alınarak hesaplandı.

\section{Bilişim ve iletişim teknoloji kullanım}

Öğrencilerin masa başında bilgisayar kullanım süreleri soru sorma yöntemi kullanıldı. Günlük ders amaçlı bilgisayar kullanımı, günlük digital oyunlar oynama, ve haftalık internet kullanımı olarak üç farklı parametre ile değerlendirildi.

\section{Hamstring uzunluğu}

Olguların hamstring uzunluğuna düz bacak kaldırma testi ile bakılmıştır. Düz bacak kaldırma testi hamstring kısalığının tespit edilmesinde oldukça yaygın olarak kullanılan bir testtir. Öğrenciden uygun kıyafetlerle sırtüstü yatar pozisyonda, karşı bacağını dizi düz olacak şekilde yatakta sabit tutması, test edilecek bacağı ise ayak bileği dorsifleksiyonda, dizi düz olacak şekilde yukarı doğru kaldırması istendi. Öğrenciye ilk gerginlik oluştuğu yerde beklemesi söylendi. Testin sonunda hamstring uzunluğu; kısa, çok kısa ve normal olarak kaydedildi (9).

\section{Reaksiyon zamanı}

Reaksiyon zamanı, Nelson El Reaksiyon testi ile değerlendirildi. Denek ön kol ve el masanın üzerinde rahat olacak biçimde sandalyeye oturdu. Başparmak ve işaret parmak uçları masadan 8-10 cm dişarıda, başparmak ve işaret parmağının üst kısımlan birbirine paralel olacak şekilde hazır duruma getirdi. Test yöneticisi cetveli, deneğin baş ve işaret parmaklarının arasında olacak şekilde tuttu. Deneğin direkt olarak cetvelin orta noktasına bakması istendi. Cetvel bırakıldığı anda cetveli baş ve işaret parmaklan ile yakalaması söylendi. Cetvel birakıldı ve deneğin cetveli yakaladı̆̆ı başparmağının üst kenarında bulunan çizgi okundu. 5 deneme yapılıp sonuçlarının ortalaması kaydedildi (10).

\section{İstatistiksel Analiz}

$\mathrm{Bu}$ çalışmada istatistiksel sonuçların elde edilmesinde SPSS 15.0 paket programından yararlanıldı. Olguların demografik ve fiziksel özellikleri frekans, aritmetik ortalama \pm Standart sapma kullanılarak belirlendi. Masa başında bilgisayar kullanım süreleri ile hamstring kas uzunluğu, reaksiyon zamanı ve vücut kitle indeksi arasındaki ilişkiyi analiz etmek için ki-kare testi kullanıldı. Anlamlılık düzeyi $p<0,05$ olarak kabul edildi.

\section{BULGULAR}

Çalışmaya alınan tüm öğrencilerin fiziksel özellikleri Tablo I'de verildi. Toplam 67 öğrencinin \%42'si k1z, \%58'i erkekti. Yaş ortalamaları $16 \pm 1,1$, ortalama boy uzunluğu $172,2 \pm 8,7 \mathrm{~cm}$ ve ortalama vücut ağırlığ

Öğrencilerin reaksiyon zamanı ile bilgisayar kullanım süreleri arasında bir ilişki saptanmamıştır $(p>0,05)$. Bilgisayar kullanım açısından cinsler arasında bir fark belirlenmemiştir $(p>0,05)$.

Haftalık 1-13 saat internet kullanan 37 öğrenciden 18'inde (\%48,6), 14-41 saat internet kullanan 18 öğrenciden 6'sında (\%33) ve 42 saat internet kullanan 9 öğrenciden 6 'sında $(\% 66,6)$ hamstring kısalığı görülmüştür. Elde edilen verilere göre, hamstring kısalığı ile haftalık internet kullanım süreleri arasındaki ilişki istatiksel açıdan anlamlı düzeyde bulunmuştur $(p<0,05)$ (Tablo II).

Her gün oyun oynamayan 45 öğrenciden 29'unun (\%64) VKİsi normal iken 1 saatten az oyun oynayan 9 öğrenciden 4'ünün VKİ'si normal, 5'inin ise düşük olarak tespit edildi. 23 saat veya 4-5 saat oyun oynayan öğrencilerin tamamının VKİ normal olarak bulundu. Ancak 5 saatten fazla bilgisayarda oyun oynayan 3 öğrenciden 2 'sinin $(\% 67,6)$ obez olduğu gözlendi. Günlük 5 saatten fazla oyun oynayan öğrencilerde obez olma riskinin yüksek olduğu tespit edilmiştir. Dijital oyun oynama süreleri ile VKİsi arasında doğrusal bir ilişki bulunmuştur $(p<0,05)$ (Tablo III). 
Tablo I. Öğrencilerin fiziksel özellikleri

\begin{tabular}{lc}
\hline Özellikler & Ortalama \pm Standart Değer \\
\hline Yaş(yıl) & $16 \pm 1,1$ \\
Boy $(\mathrm{cm})$ & $172,2 \pm 8,7$ \\
Kilo(kg) & $64,3 \pm 14,5$ \\
Cinsiyet $(\%)$ & \\
$\quad$ Kiz & $28(48)$ \\
$\quad$ Erkek & $39(52)$ \\
BKI & $21,52 \pm 3,22$ \\
\hline
\end{tabular}

Tablo II. Hamstring Kısalığı ile haftalık internet kullanım süreleri arasındaki ilişki

\begin{tabular}{lccccc}
\hline \multicolumn{5}{c}{ Haftalık internet kullanım süreleri } \\
\hline Hamstring kısalı̆̆ı & Kullanmiyorum & $\mathbf{1 ~ - 1 3 ~ s a a t ~}$ & $\mathbf{1 4} \mathbf{- 4 1}$ saat & 42 saat & Total \\
\hline Normal & 0 & 19 & 12 & 3 & 34 \\
Kısa & 1 & 16 & 6 & 5 & 28 \\
Çok kisa & 1 & 2 & 0 & 1 & 5 \\
Total & 2 & 37 & 18 & 9 & 67 \\
\hline
\end{tabular}

$(p<0,05)$

Tablo III. Vücut kitle İndeksi ile Günlük digital oyun oynama süreleri arasındaki ilişki

\begin{tabular}{|c|c|c|c|c|c|c|}
\hline \multirow{2}{*}{$\begin{array}{l}\text { Vücut kitle } \\
\text { indeksi }\end{array}$} & \multicolumn{6}{|c|}{ Günlük digital oyun oynama süreleri } \\
\hline & $\begin{array}{c}\text { Oynamıyorum yada } \\
\text { Her gün değil }\end{array}$ & 1 saatten az & 2-3 saat & 4-5 saat & 5 saatten fazla & Total \\
\hline$<18,5$ (zayıf) & 9 & 5 & 0 & 0 & 0 & 14 \\
\hline $\begin{array}{l}18,5-24,99 \\
\text { (normal) }\end{array}$ & 29 & 4 & 7 & 3 & 1 & 44 \\
\hline $\begin{array}{l}25-29,99 \\
\text { (Şişman) }\end{array}$ & 4 & 0 & 0 & 0 & 2 & 6 \\
\hline $\begin{array}{l}\geq 30 \\
\text { (Çok şişman) }\end{array}$ & 3 & 0 & 0 & 0 & 0 & 3 \\
\hline Total & 45 & 9 & 7 & 3 & 3 & 67 \\
\hline
\end{tabular}

\section{TARTIŞMA}

Çalışmamızda, adolesan dönemde ekrana bağlı aktivitelerin hamstring kas uzunluğu, reaksiyon zamanı ve vücut kitle indeksi üzerine etkisini değerlendirildi. Haftalık internet kullanım süresi arttıkça hamstring kısalığı görülen öğrenci yüzdesinin arttığı saptanmıştır. Ayrıca günlük 5 saatten fazla oyun oynayan öğrencilerde obezite gelişme riskinin çok yüksek olduğu tespit edilmiştir ve dijital oyun oynama süreleri ile vücut kitle indeksi arasında doğrusal bir ilişki bulunmuştur.

Çocuklar ve gençler giderek artan oranlarda bilgisayar ve interneti kullanmaktadır. Uzun süre kontrolsüz masa başı bilgisayar ve internet kullanımı çocuk / gencin fiziksel, psikolojik, sosyal, bilişsel sağlığını ve yaşamını olum- 
suz yönde etkilemektedir. Araştırmalar Avustralya'da çocukların \%99'unun 11-14 yaşları arasında bilgisayar kullanmaya başladığını, Amerika Birleşik Devletlerinde ise çocukların günde 60 dakikadan fazla süre bilgisayar karşısında vakit harcadıklarını ve ergenlerin \%64'ünün bilgisayar kullandığını göstermektedir $(11,12)$. Artan bilgisayar kullanımının gençlerde kas-iskelet sisteminin gelişimini etkilediği, doğrudan veya postüral alışkanlıkları değiştirmesi nedeniyle dolaylı olarak kas-iskelet rahatsızlık riskini arttırdığı belirtilmektedir (11-13). Çalışmamızda da hamstring kısalığı ile haftalık internet kullanım süreleri arasında istatiksel açıdan anlamlı bir ilişki bulunmuştur.

Adelosanlarda yapılan çalışmalar iletişim teknolojileri ile özellikle bilgisayar kullanımı ile kas iskelet sistem problemleri arasındaki ilişkiyi ortaya koymuştur. Baş ağrıları, boyun-omuz problemleri ve bel problemleri gibi birçok kas iskelet sistemine ait problemler bilgisayar kullananlarda kullanmayanlara oranla oldukça yaygındır ve bilgisayar başında geçen süre arttıkça kas iskelet sistemine ait sorunların oluşma riski de artmaktadır $(14,15)$. Hakala ve ark yaptıkları çalışmada bilgisayar karşısında uzun süre sabit pozisyonda oturmanın kassal problemlerin oluşma riskini arttırdığını bulmuşlardır (4). Çalışmamızda, haftalık 1-13 saat internet kullanan öğrencilerin \%48,6'sında hamstring kas kısalığ 1 gözlenmiştir. ayrıca 1441 saat internet kullananların \%33'ünde ve 42 saat internet kullananların \%66,6'sında hamstring kısalığ miştir. Sonuç olarak internet kullanım süresi arttıkça hamstring kas kısalığı görülme riski artmaktadır. İnternet kullanımındaki statik uzun süreli oturma pozisyonunun bu kas grubundaki kısalmada etkili olduğu düşünülmektedir.

Stettler ve ark yaptıkları çalışmalarında elektronik oyun oynama ve obesite arasında anlamlı bir ilişki bulmuşlardır. Günlük oyun için harcanan her bir saatin obesite riskini 2 kat arttırdığını rapor etmişlerdir (16). Benzer şekilde Lajunen ve ark yaptıkları çalışmalarında evde bilgisayar kullanımının aşırı kilo alma riskini anlamlı bir şekilde arttırdığını bulmuşlardır (17). Ebstein ve ark randomize kontrolu bir çalışmalarında televizyon ve bilgisayar kullanımının azaltılmasının obesitenin önlenmesinde ve BKİ'nin azaltılmasında önemli rol oynadığını tespit etmişlerdir (18). Bu çalışmada her gün bilgisayar ba- şında oyun oynamayan öğrencilerin \%64'ünün vücut kitle indeksi normal sinırlarda bulunmuştur. 1 saatten az oyun oynayan 9 öğrenciden 5'inin zayıf, 4'ünün ise normal vücut ağırlığına sahip olduğu saptanmıştır. Ancak 5 saatten fazla dijital oyun oynayan öğrencilerin $\% 67,6$ 'sinda belirgin kilo artışı göze çarpmaktadır. Masa başında dijital oyun oynama süreleri ile vücut kitle indeksi arasında doğrusal bir ilişki göstermektedir. Son zamanlarda hem kız hem de erkek çocukların zamanlarının büyük bir kısmını masa başında dijital oyun oynama ile geçirmeleri beraberinde fiziksel aktivite sürelerinin kısalması ve hazır besinlerin tüketimindeki artmanın bu sonuçları etkilediğini söyleyebiliriz.

\section{KISITLILIKLAR}

Çalışmamız İzmir ilindeki özel bir okulda okuyan öğrenciler üzerinde gerçekleştirilmiştir. Ulaşılabilen öğrenci sayısının azlığı ve tek bir okulda yapılması çalışma verilerimizin genellenmesinin özündeki en önemli kısıtlılıktır. Bu konuda daha kapsamlı çalışmaların yapılmasına ihtiyaç vardır.

\section{SONUÇ}

Her geçen gün yaşamımızda daha çok yer edinen bilgisayarların, olumlu birçok katkısının yanı sıra, bir kısım sağlık sorununu da beraberinde getirmektedir. Bu tarz sağlık sorunları oldukça yaygın olarak görülmekle birlikte önemli işgücü ve ekonomik kayıplara da neden olabilmektedir. Buna karşın erken yaşta alınabilecek bazı basit önlemlerle önemli ölçüde benzeri sorunlar azaltılabilmekte yada sorunlar oluşmadan önüne geçilebilmektedir.

Günümüzde gelişmiş dünya ülkelerinin neredeyse hepsinde koruyucu sağlık eğitimi ilkokul düzeyinden başlamaktadır. Gençlerin bu anlamda bilinçlendirilmesi oluşabilecek fiziksel sorunların minimalize edilmesinde en etkili yöntemlerden biri olarak kabul edilebilir, bu amaçla sağlık dersi veya beden eğitimi ders müfredatına eklenebilecek koruyucu yöntemlerin anlatımı veya okullarda belirli dönemlerde konunun uzmanları tarafından verilebilecek seminer programlarıla gençlerin eğitilmesi ve bilinçlendirilmesi hedeflenmelidir.

\section{KAYNAKLAR}

1. Must A, Bandini LG, Tybor DJ, Phillips SM, Naumova EN, Dietz WH. Activity, inactivity, and screen time in 
relation to weight and fatness over adolescence in girls. Obesity 2007;15:1774-1781.

2. Van der Wal, De Vet. Neck/Shoulder, Low Back, and Arm Pain in Relation to Computer Use, Physical Activity, Stress, and Depression Among Dutch Adolescents. Pediatrics 2006;117:412-416.

3. Sheilds M. Overweight and obesity among children and youth. Health Reports 2006;17:27-42.

4. Hakala PT, Rimpela AH, Saarni LA, et al. Frequent computer-related activities increase the risk of neckshoulder and low back pain in adolescents. European Journal of Public Health 2006;16: 536-541.

5. Liou YM, Liou T-H, Chang L-C. Obesity among adolescents: sedentary leisure time and sleeping as determinants. Journal of Advanced Nursing 2010;66:12461256.

6. Mota J, Ribeiro J, Santos MP, Gomes H. Obesity, physical activity, computer use, and television viewing in Portuguese adolescents. Pediatric Exercise Science 2006;18:113-121.

7. Boone JE, Gordon-Larsen P, Adair LS, Popkin BM. Screen time and physical activity during adolescence: longitudinal effects on obesity in young adulthood. International Journal of Behavioral Nutrition and Physical Activity 2007; 4: 26.

8. Torsheim T, Eriksson L, Schnohr CW, Hansen F, Bjarnason T, Välimaa R. Screen-based activities and physical complaints among adolescents from the Nordic countries. BMC Public Health 2010;10:324

9. Otman S, Demirel H, Sade A. Tedavi Hareketlerinde Temel Değerlendirme Prensipleri. Ankara 1995;37-39.
10. Ergun N, Baltacı G. Spor yaralanmalarında Fizyoterapi ve Rehabilitasyon Prensipleri. Ankara 1997; 94-96.

11. Leon M. Straker, Peter B. O'Sullivan Anne Smith, Mark Perry. Computer Use and Habitual Spinal Posture in Australian Adolescents. Public Health Reports September - October 2007;122:634-643.

12. Greig A, Straker L, Briggs A. Cervical erector spinae and upper trapezius muscle activity in children using different information technologies. Physiotherapy 2005;91: 119-126.

13. Kelly G, Dockrell S, Galvin R. Computer use in school: Its effect on posture and discomfort in schoolchildren. Work 2009;32: 321-328.

14. Alexander LM, Currie C. Young people's computer use: implications for health education. Health Educ 2004;4: 254-261.

15. Costigan SA, Barnett L, Plotnikoff RC, Lubans DR. The health indicators associated with screen-based sedentary behavior among adolescent girls: a systematic review. J Adolesc Health 2013;52:382-392.

16. Stettler N, Signer TM, Suter PM. Electronic games and environmental factors associated with childhood obesity in Switzerland. Obes Res 2004;12: 896-903.

17. Lajunen HR, Rahkonen AR. Are computer and cell phone use associated with body mass index and overweight. A population study among twin adolescents BMC Public Health 2007;7:24

18. Epstein LH, Roemmich JN, Robinson JL, et al. A randomized trial of the effects of reducing television viewing and computer use on body mass index in young children. Arch Pediatr Adolesc Med 2008;162:239-245. 